\title{
COEFICIENTE DE REAERAÇÃO EM TRÊS TRECHOS DO RIO POMBA (MG), OBTIDOS NOS PERÍODOS CHUVOSO E SECO
}

Antonio Teixeira de Matos ${ }^{1}$, Thomé Vidigal de Almeida ${ }^{2}$, Demetrius David da Silva ${ }^{3}$, José de Alencar Pinto Farage ${ }^{4}$

\section{RESUMO}

Para caracterização do potencial de autodepuração do curso d'água, foi determinado o coeficiente de reaeração $\left(\mathrm{K}_{2}\right)$ em três trechos do Rio Pomba, Minas Gerais, Brasil, em dois períodos distintos do ano de 2005 (de julho a agosto e de outubro a novembro). $\mathrm{O}$ valor de $\mathrm{K}_{2}$ foi obtido por cálculo, com a substituição das variáveis temperatura da água, altitude local, concentração de $\mathrm{OD}$ no ponto de mistura, $\mathrm{DBO}_{5 \mathrm{~d}-20^{\circ} \mathrm{C}}$, velocidade, valor de $\mathrm{K}_{1}$, distância percorrida e concentração de OD no final do trecho na equação de Streeter-Phelps. Foram obtidos valores de $\mathrm{K}_{2}$ entre 0,4 a 2,0 $\mathrm{d}^{-1}$, no período seco, e entre 0,6 a $0,9 \mathrm{~d}^{-1}$, no período chuvoso. Os maiores valores de $\mathrm{K}_{2}$ foram obtidos na região de relevo mais montanhoso, onde o Rio Pomba é mais raso e turbulento. Equações matemáticas de $\mathrm{K}_{2}$ como função da velocidade e profundidade do curso d'água também foram ajustadas, utilizando-se o modelo potencial.

Palavras-chave: autodepuração, coeficiente de oxigenação, qualidade da água

\section{ABSTRACT \\ REAERATION COEFFICIENT FOR THREE STRETCHES OF THE POMBA RIVER (MG) GOTTEN IN THE RAINY AND DRY PERIODS}

For characterization the potential of self-purification of the course of water, it was obtained the reaeration coefficient $\left(\mathrm{K}_{2}\right)$ in three streches of the Pomba River, Minas Gerais State, Brazil, in two different periods of the year of 2005 (of July to August and of October to November). The $\mathrm{K}_{2}$ value was gotten by calculation, with the variables water temperature, local altitude, dissolved oxygen concentration (OD) in the mixture point, BOD, water speed, deoxigenation coefficient $\left(\mathrm{K}_{1}\right)$, traveled distance and OD concentration in the end of the passage) substitution in the Streeter-Phelps (1925) equation. The $\mathrm{K}_{2}$ values were among 0.4 to $2.0 \mathrm{~d}^{-1}$, in the dry period, and among 0.6 to $0.9 \mathrm{~d}^{-1}$, in the period rainy. The highest values of $\mathrm{K}_{2}$ they came in the area of more mountainous relief, where the Pomba River was more shallow and turbulent. Mathematical equations of $\mathrm{K}_{2}$ as function of the speed and depth of the course of water were also adjusted, being used the potential model.

Keywords: self-purification, oxygenation coefficient, water quality

Recebido para publicação em 07/03/2008. Aprovado em 19/03/2010.

1- Engenheiro Agrícola, Professor do Departamento de Engenharia Agrícola, UFV, e-mail: atmatos@ufv.br

2- Agrônomo, Mestre em Engenharia Agrícola, Área de Recursos Hídricos e Ambientais, CEFET Rio Pomba; thome@cefetrp.edu.br

3- Agrônomo, Professor do Departamento de Engenharia Agrícola, UFV, e-mail: david@ufv.br

4- Engenheiro Agrícola, Professor da UNIPAC- Leopoldina; e-mail: alencar.farage@yahoo.com.br 


\section{INTRODUÇÃO}

A autodepuração de um curso d'água é o balanço entre a taxa de desoxigenação, imposta pela oxidação da matéria orgânica, e a taxa de reaeração, na qual a reaeração atmosférica é o principal componente.

Quando a água é exposta a um gás, ocorre contínuo intercâmbio de moléculas da fase líquida para a gasosa e vice-versa. Tão logo a concentração de solubilidade na fase líquida seja atingida, ambos os fluxos passam a ser de igual magnitude, de modo a não ocorrer uma mudança global nas concentrações do gás em ambas as fases. Este equilíbrio dinâmico define a concentração de saturação $\left(\mathrm{C}_{\mathrm{s}}\right)$ do gás na fase líquida (VON SPERLING, 1996).

Os pesquisadores Streeter \& Phelps (1925) estabeleceram as bases matemáticas da curva de oxigênio dissolvido em um curso d'água. A estrutura do modelo proposto por eles é clássica em estudos na área da engenharia de recursos hídricos e ambientais, servindo de suporte para todos os outros modelos mais sofisticados que se sucederam. Para a situação relativamente simples em que se considera apenas a desoxigenação e a reaeração atmosférica no balanço do oxigênio dissolvido, a taxa de variação do déficit de oxigênio com o tempo pode ser expressa pela seguinte equação diferencial, advinda da interação das equações de desoxigenação e reaeração:

Taxa de variação do déficit de $O D=$ Consumo de $O D$ - Produção de OD

$$
\frac{d D}{d t}=K_{1} \times L-K_{2} \times D
$$

em que,

D - déficit de oxigênio dissolvido, ou seja, a diferença entre a concentração de saturação $\left(\mathrm{C}_{\mathrm{s}}\right)$ e a concentração existente em um tempo $\mathrm{t}\left(\mathrm{mg} \mathrm{L}^{-1}\right)$; $\mathrm{t}$ - tempo (d);

$\mathrm{K}_{1}$ - coeficiente de desoxigenação $\left(\mathrm{d}^{-1}\right)$;

$\mathrm{K}_{2}$ - coeficiente de reaeração na base "e" $\left(\mathrm{d}^{-1}\right)$;

$\mathrm{L}$ - DBO remanescente em um tempo $t$ qualquer (mg L-1).

A integração desta equação conduz a:
$D_{t}=\frac{K_{1} \times L_{0}}{K_{2}-K_{1}} \times\left(e^{-K_{1} \times t}-e^{-K_{2} \times t}\right)+D_{0} \times e^{-K_{2} \times t}$

em que,

$\mathrm{D}_{\mathrm{t}}$ - déficit de oxigênio num ponto $\mathrm{t}$ qualquer $\left(\mathrm{mg} \mathrm{L}^{-1}\right)$;

$\mathrm{L}_{\mathrm{o}}$ - DBO última no ponto de mistura $\left(\mathrm{mg} \mathrm{L}^{-1}\right)$;

$\mathrm{D}_{\mathrm{o}}$ - déficit de oxigênio no ponto de mistura $\left(\mathrm{mg} \mathrm{L}^{-1}\right)$ ou seja diferença entre a concentração de OD na mistura e nas condições de saturação.

A variação da concentração de oxigênio em função do tempo é expressa, então, pela Equação 4:

$C_{t}=C_{s}-D_{t}$

em que,

$\mathrm{C}_{\mathrm{t}}$ - concentração de OD em um dado instante $\mathrm{t}$ $\left(\mathrm{mg} \mathrm{L}^{-1}\right)$;

$\mathrm{C}_{\mathrm{s}}$ - concentração de saturação do $\mathrm{OD}\left(\mathrm{mg} \mathrm{L}^{-1}\right)$.

Assim, pela Equação 5, de Streeter-Phelps (1925), a concentração de $C_{t}$ pode ser obtida por:

$C_{t}=C_{s}-\left[\frac{K_{1} \times L_{0}}{\left(K_{2}-K_{1}\right)} \times\left(e^{-K_{1} \times t}-e^{-K_{2} \times t}\right)+D_{0} \times e^{-K_{2} \times t}\right]$

em que,

$\mathrm{D}_{\mathrm{o}}$ - déficit inicial de OD na água, logo após o ponto de mistura $\left(\mathrm{mg} \mathrm{L}^{-1}\right)$.

O coeficiente de reaeração é uma variável de grande importância nos modelos de autodepuração de curso d'água, entretanto é de difícil obtenção já que depende das características geométricas do rio, da velocidade da água, presença ou não de corredeiras e quedas, além da capacidade do meio em difundir o oxigênio.

Segundo Fair et al. (1973) e Arceivala (1981), citados por von Sperling (1996), os valores de $\mathrm{K}_{2}$ variam de 0,12 a até mais de $1,61 \mathrm{~d}^{-1}$, o que depende da profundidade e velocidade do curso d'água.

A partir de estudos conduzidos por diversos autores em rios naturais e artificiais, foram obtidas várias equações empíricas, baseadas em 
características hidráulicas dos rios estudados, que podem ser utilizadas na estimativa do valor de $\mathrm{K}_{2}$, mas ainda não se sabe qual modelo físico é mais apropriado para a descrição do fenômeno, se o da teoria da renovação da superfície ou o da teoria dos dois filmes (RIBEIRO, 2001).

O modelo potencial, tal como apresentado na Equação 6, tem sido muito utilizado no ajuste de equações de $\mathrm{K}_{2}$ como função da velocidade e profundidade do curso d'água.

$K_{2}=a \cdot v^{b} \cdot H^{-c}$

em que,

$\mathrm{v}$ - velocidade média do curso d'água $\left(\mathrm{m} \mathrm{s}^{-1}\right)$;

$\mathrm{H}$ - profundidade média do curso d'água $(\mathrm{m})$.

Owens et al. (1976), citados por von Sperling (1996), ajustaram o modelo potencial para rios com $\mathrm{H}$ entre 0,1 e $0,6 \mathrm{~m}$ de profundidade e velocidade entre 0,05 e $1,5 \mathrm{~m} \mathrm{~s}^{-1}$, obtendo a seguinte equação:

$$
K_{2}=5,3 \times v^{0,67} \times H^{-1,85}
$$

Ribeiro (2001) apresentou uma equação geral, que pode ser utilizada para a determinação de $\mathrm{K}_{2}$ em rios:

$$
K_{2}=\frac{294 \times\left(D_{L} \times v\right)^{0,5}}{H^{1,5}}
$$

em que,

$\mathrm{D}_{\mathrm{L}}$ - coeficiente de difusão molecular do oxigênio $\left(\mathrm{m}^{2} \mathrm{~d}^{-1}\right)$.

Na maioria dos trabalhos consultados, o valor de $\mathrm{K}_{2}$ é obtido utilizando-se equações empíricas (PALMA-SILVA et al., 2007), tal como algumas já apresentadas, ou determinados com a calibração de modelos de autodepuração (BÁRBARA, 2006). Estimativas efetuadas exclusivamente para $\mathrm{K}_{2}$ podem ser efetuadas utilizando-se dados obtidos em trechos homogêneos de rios, nesse caso, utilizase a Equação 5, na qual $\mathrm{K}_{2}$ seria a única variável não conhecida. Dessa forma, evita-se a utilização de equações ajustadas para condições ambientais diferentes das brasileiras e por evitar a influência de variáveis, também não conhecidas, quando da calibração de modelos mais complexos.

Com a realização deste trabalho, objetivou-se obter o coeficiente de reaeração $\left(\mathrm{K}_{2}\right)$ e equações para sua estimativa como função da velocidade e profundidade, em três diferentes trechos do Rio Pomba e em duas épocas distintas do ano.

\section{MATERIAL E MÉTODOS}

O Rio Pomba nasce nas proximidades de Barbacena-MG, na Serra do Sapateiro (ramificação da Mantiqueira), em um trecho localmente denominado Serra da Conceição, a cerca de 1.100 $\mathrm{m}$ de altitude, percorrendo cerca de $290 \mathrm{~km}$ no sentido sudeste, até finalmente desaguar no Rio Paraíba do Sul, em altitude aproximada de $60 \mathrm{~m}$ (SANTIAGO, 1991).

O trecho em estudo compreende os primeiros 74 quilômetros do Rio Pomba, do Município de Santa Bárbara do Tugúrio ao Município de Rio Pomba. Para caracterização física e qualitativa desse trecho da Bacia Hidrográfica do Rio Pomba, seis pontos de amostragem foram previamente selecionados, de forma a se estabelecer trechos considerados homogêneos, sendo geoposicionados, utilizandose GPS e cartas topográficas, na escala de 1:50.000, do IBGE, vetorizadas com a utilização do software TRACKMAKER PRO, conforme apresentado na Figura 1.

Os seis pontos de amostragem representaram o início e final dos trechos estudados no Rio Pomba. Assim, com dados dos pontos I e II, III e IV, V e VI, foram obtidos dados para estimativa do coeficiente de reaeração nos trechos T1, T2 e T3, respectivamente.

O primeiro trecho (T1) ficou compreendido entre um ponto imediatamente a jusante do local de esgotamento sanitário da cidade de Santa Bárbara de Tugúrio (P-II) até um ponto imediatamente à montante da confluência do Rio Pomba com o Rio Paciência (P-III), numa extensão de 36 km; o segundo trecho (T2) ficou compreendido entre P-IV e P-V, estando P-IV posicionado a jusante do local de esgotamento sanitário da cidade de Mercês e P-V, na confluência do Rio Pomba com o Rio São Manoel, numa extensão de 26 km; e o 
terceiro trecho (T3), compreendido entre P-VI e P-VII, estando P-VI posicionado a jusante do esgotamento sanitário na cidade de Rio Pomba e o P-VII, imediatamente a montante da cidade de Guarani.

As amostragens de água e medições necessárias para obtenção dos coeficientes de desoxigenação $\left(\mathrm{K}_{1}\right)$ e de reaeração $\left(\mathrm{K}_{2}\right)$, no período denominado "seco", foram realizadas em quatro ocasiões diferentes, de 04 de julho a 01 de agosto e as do período denominado "chuvoso" de 03 de outubro a 31 de outubro de 2005. As medições da profundidade e velocidade média da água no rio foram efetuadas em quatro ocasiões diferentes no período seco (de 05 de julho a 25 de agosto) e chuvoso (de 04 de outubro a 17 de novembro), no mesmo ano.

Para análise da distribuição pluviométrica no período de coleta de dados nos trechos avaliados da Bacia Hidrográfica do Rio Pomba, foram analisados dados (série histórica de 1960 a 1994) da Estação Pluviométrica Usina de Ituerê, localizada no município de Rio Pomba, na latitude de $21^{\circ} 18^{\prime} 00^{\prime \prime}$ longitude de $43^{\circ} 13^{\prime} 00^{\prime}$, altitude de 512 m, disponibilizados pela Agência Nacional das Águas.
As amostras ( $1 \mathrm{~L}$ de amostra por ponto de amostragem) coletadas para a obtenção do IQA e do coeficiente de desoxigenação $\left(\mathrm{K}_{1}\right)$ foram do tipo simples, coletadas na superfície $(0,20-0,30$ metros de profundidade) do rio e, preferencialmente, na posição central da calha principal do Rio Pomba. As coletas foram feitas a vau nas seções de menor profundidade e em embarcação nos pontos de maior profundidade.

A medição da velocidade média da água em cada local de amostragem da água foi feita utilizandose um micromolinete, OTT-C2, com hélice de 50 $\mathrm{mm}$. A profundidade média da seção transversal do curso d'água foi obtida por meio de levantamento batimétrico do local (AZEVEDO NETTO et al., 1998).

As amostras coletadas de água foram acondicionadas em caixa de isopor contendo gelo e transportadas ao Laboratório de Qualidade da Água, do Departamento de Engenharia Agrícola da UFV, onde foram processadas as análises.

Os valores de $\mathrm{K}_{1}$ foram obtidos após a incubação de mistura das amostras com solução nutriente em estufa tipo BOD, sob temperatura de $20{ }^{\circ} \mathrm{C}$, por um período de 21 dias, determinandose a DBO exercida, pelo método Winkler

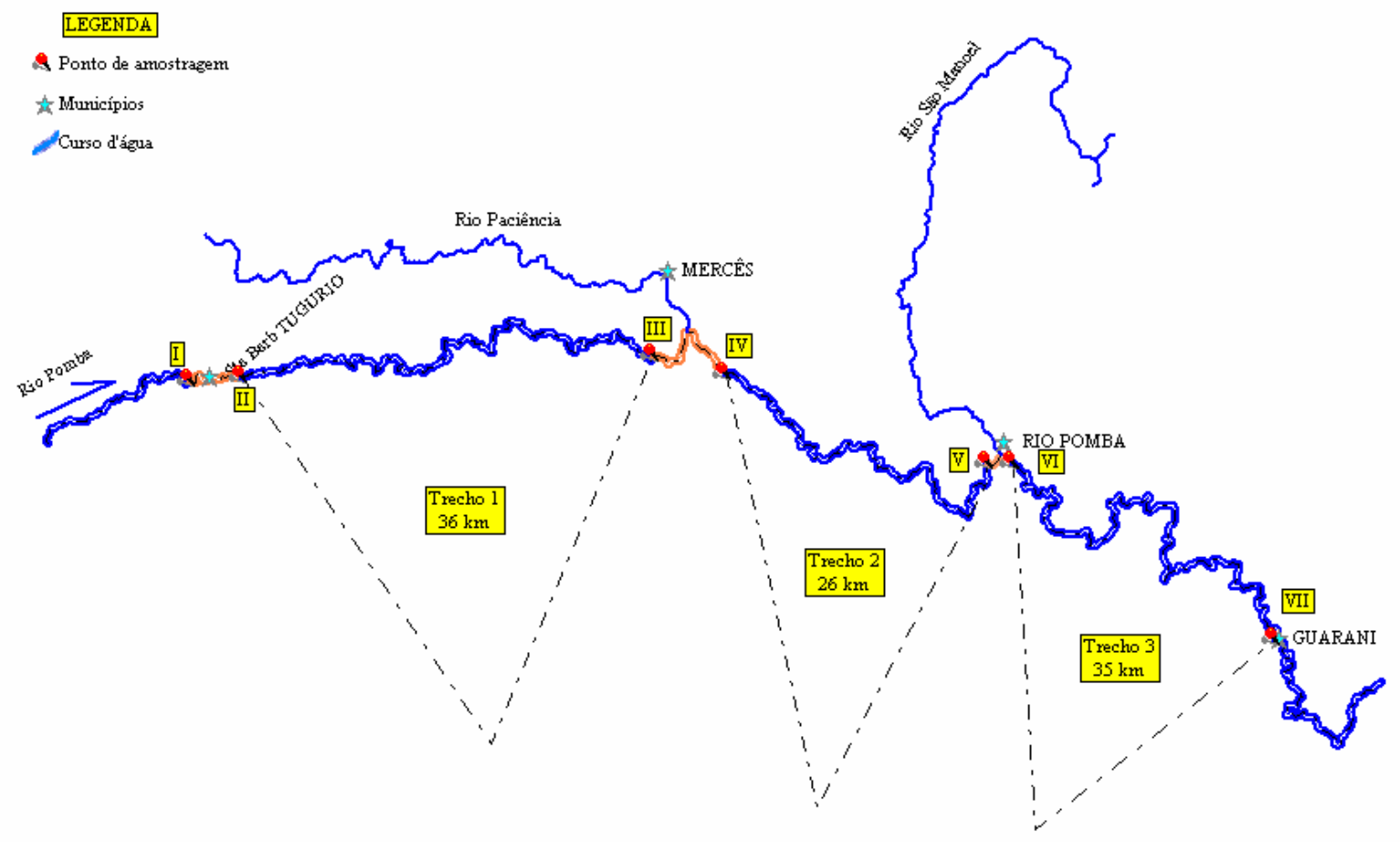

Figura 1. Localização do trecho de estudo do Rio Pomba, em Minas Gerais 
(iodométrico) (APHA, 1998), ao longo do período de avaliação. Aos dados obtidos, foram ajustadas equações de regressão não linear, de forma a se obter os parâmetros $\mathrm{K}_{1}$ e $\mathrm{L}_{\mathrm{o}}$, conforme a equação apresentada por von Sperling (1996):

$Y=L_{0^{\prime}}\left(1-e^{-K 1 . t)}\right.$

em que,

Y é a DBO exercida $\left(\mathrm{mg} \mathrm{L}^{-1}\right)$

$\mathrm{O}$ coeficiente de reaeração $\left(\mathrm{K}_{2}\right)$ foi obtido substituindo-se, na Equação 5, de Streeter-Phelps (1925), os dados de entrada (temperatura da água, altitude local, concentração de OD no ponto de mistura, $\mathrm{DBO}_{5 \mathrm{~d}-20^{\circ} \mathrm{C}}$, velocidade, valor de $\mathrm{K}_{1}$, distância percorrida e a concentração de OD no final do trecho). Todas as variáveis foram obtidas com quatro repetições, de forma a se permitir quatro estimativas de $\mathrm{K}_{2}$. Os valores obtidos foram submetidos à análise de variância e, em caso de significância de alguma fonte de variação, foi realizado o teste de médias (Tukey, 10\% de probabilidade).

Os valores de profundidade e velocidade do curso d'água nos diferentes trechos e nas duas épocas do ano foram utilizados para ajuste da Equação 6, estimando-se seus parâmetros por regressão não linear. Esses dados também foram utilizados para cálculo do valor de $\mathrm{K}_{2}$ utilizando-se as equações $7 \mathrm{e}$ 8 , a fim de se verificar a confiabilidade das mesmas nas estimativas desta variável para o trecho estudado do Rio Pomba.

\section{RESULTADOS E DISCUSSÃO}

Utilizando-se os dados pluviométricos obtidos na Estação Pluviométrica Usina de Ituerê, foram plotadas as curvas das Normais (série histórica de 1960 a 1994) e da precipitação ocorrida em 2005, o que está apresentado na Figura 2. Verifica-se, com base nas setas indicativas do período de medição e coleta de amostras, que o ano de 2005 apresentou um período seco típico, ocorrendo baixo índice pluviométrico no período de julho a agosto. $\mathrm{O}$ período chuvoso ficou um pouco alterado, ocorrendo precipitações abaixo do normal no início de outubro e acima do normal do meado de outubro até o final do ano.

No Quadro 1, estão apresentados os valores da velocidade média e profundidade média, variáveis estas que influenciam diretamente no valor de $\mathrm{K}_{2}$.

Pode-se observar que, em todos os trechos analisados, com a diminuição na profundidade média do rio houve decréscimo na velocidade da água, ocorrendo o contrário, no caso de aumento na profundidade média do curso d'água. Analisandose a Equação 6, pode-se verificar que a velocidade está diretamente e a profundidade inversamente proporcional a $\mathrm{K}_{2}$. Portanto, mesmo em trechos onde se registrou aumento na velocidade média não quer dizer que houve aumento no valor de $\mathrm{K}_{2}$, pois a maior profundidade do curso d'água proporcionou influência inversa no valor desta variável.

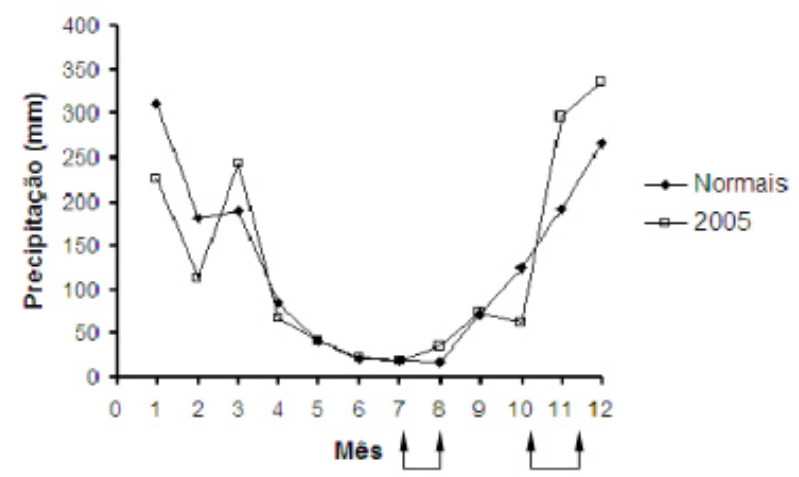

Figura 2. Distribuição de chuvas normal e no ano de 2005 na Bacia Hidrográfica do Rio Pomba (MG), tomando-se como referencial os dados obtidos na Estação Pluviométrica da Usina Ituerê.

As setas indicam o período de medições e coleta de amostras

Nos dados apresentados no Quadro 1, há de se estranhar a ocorrência de menores profundidades médias do Rio Pomba no período chuvoso que no período seco, especialmente no trecho 1. Acreditase que as menores profundidades observadas nas duas primeiras medições (R1 e R2) possam ser justificadas pelo baixo índice pluviométrico ocorrido na bacia hidrográfica no início de outubro, ocasião em que foram feitas essas medições. Além disso, existem algumas centrais hidrelétricas a montante que, por questões operacionais, podem ter interferido na vazão de água no rio. 
Quadro 1. Valores obtidos de velocidade média $\left(\mathrm{v}_{\text {med }}\right)$ e profundidade média $\left(\mathrm{p}_{\text {med }}\right)$, nos três trechos estudados do Rio Pomba, nos períodos seco e chuvoso

\begin{tabular}{llcccccc}
\hline \multirow{3}{*}{ Período } & \multirow{2}{*}{ Medição } & \multicolumn{2}{c}{ T1 } & \multicolumn{2}{c}{ T2 } & \multicolumn{2}{c}{ T3 } \\
\cline { 3 - 8 } & & $\mathbf{v}_{\text {med }}$ & $\mathbf{p}_{\text {med }}$ & $\mathbf{v}_{\text {med }}$ & $\mathbf{p}_{\text {med }}$ & $\mathbf{v}_{\text {med }}$ & $\mathbf{p}_{\text {med }}$ \\
\cline { 3 - 8 } & $\mathrm{m} \mathrm{s}^{-1}$ & $\mathrm{~m}$ & $\mathrm{~m} \mathrm{~s}^{-1}$ & $\mathrm{~m}$ & $\mathrm{~m} \mathrm{~s}^{-1}$ & $\mathrm{~m}$ \\
\hline \multirow{3}{*}{ Seco } & R1 & 0,246 & 0,40 & 0,259 & 0,66 & 0,369 & 0,94 \\
& R2 & 0,221 & 0,38 & 0,233 & 0,63 & 0,352 & 0,92 \\
& R3 & 0,204 & 0,35 & 0,221 & 0,61 & 0,331 & 0,89 \\
& R4 & 0,195 & 0,32 & 0,216 & 0,58 & 0,306 & 0,87 \\
\hline \multirow{3}{*}{ Chuvoso } & R1 & 0,170 & 0,28 & 0,250 & 0,62 & 0,348 & 0,93 \\
& R2 & 0,195 & 0,30 & 0,284 & 0,64 & 0,357 & 0,99 \\
& R3 & 0,225 & 0,32 & 0,301 & 0,67 & 0,437 & 1,03 \\
& R4 & 0,238 & 0,34 & 0,301 & 0,74 & 0,446 & 1,16 \\
\hline
\end{tabular}

Quadro 2. Coeficientes de reaeração $\left(\mathrm{K}_{2}\right)$, obtidos em três trechos do Rio Pomba, no período seco

\begin{tabular}{|c|c|c|c|c|c|}
\hline Trecho & $\mathbf{R} 1$ & $\mathbf{R 2}$ & R3 & R4 & Média \\
\hline & & 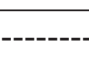 & $\left.\right|^{-1}-\cdots$ & --.-- & \\
\hline $\mathrm{T} 1$ & 1,32 & 1,13 & 1,92 & 2,05 & 1,61 \\
\hline $\mathrm{T} 2$ & 0,43 & 0,40 & 0,46 & 0,54 & 0,46 \\
\hline $\mathrm{T} 3$ & 0,75 & 0,63 & 0,71 & 0,74 & 0,71 \\
\hline
\end{tabular}

Quadro 3. Coeficientes de reaeração $\left(\mathrm{K}_{2}\right)$, obtidos em três trechos do Rio Pomba, no período chuvoso

\begin{tabular}{|c|c|c|c|c|c|}
\hline Trecho & $\mathbf{R} 1$ & $\mathbf{R 2}$ & R3 & $\mathbf{R 4}$ & Média \\
\hline & \multicolumn{5}{|c|}{ 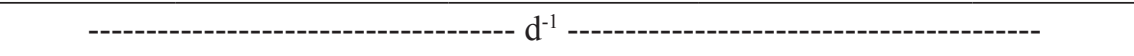 } \\
\hline $\mathrm{T} 1$ & 0,93 & 0,85 & 0,87 & 0,76 & 0,85 \\
\hline $\mathrm{T} 2$ & 1,01 & 0,89 & 0,79 & 0,16 & 0,71 \\
\hline T3 & 0,67 & 0,67 & 0,81 & 0,77 & 0,73 \\
\hline
\end{tabular}

Valores obtidos de $\mathrm{K}_{2}$, utilizando a equação de Streeter-Phelps (1925), para os três trechos estudados do Rio Pomba, nos dois períodos estabelecidos, estão apresentados nos Quadros 2 e 3.

A anormal diminuição na profundidade do rio no início do período chuvoso (repetições R1 e R2), verificada especialmente no trecho 1 , provocou diminuição na velocidade da água, o que, acreditase, tenha sido um dos fatores de influência nos relativamente baixos valores obtidos para $\mathrm{K}_{2}$.

A análise de variância das fontes de variação indicaram efeito significativo do trecho do rio, mas não da época do ano em que foi obtido $\mathrm{K}_{2}$, talvez em decorrência da inversão ocorrida na velocidade do rio, medida nas primeiras campanhas efetuadas no período chuvoso. Em vista disso, pode-se concluir que os dados obtidos, no período seco, para $\mathrm{K}_{2}$ no Rio Pomba não diferiram dos obtidos no período chuvoso de 2005.
No teste de médias (Tukey, $10 \%$ de probabilidade), os valores de $\mathrm{K}_{2}$ obtidos para o trecho 1 foram superiores aos obtidos nos trechos 2 e 3 , os quais, por sua vez, não diferiram entre si.

$\mathrm{O}$ primeiro trecho (T1) do Rio Pomba é caracterizado por ser montanhoso, com a presença de muitas corredeiras enquanto os outros dois são mais planos. Segundo von Sperling (1996), corpos d'água mais rasos e mais velozes, tendem a possuir maior coeficiente de reaeração, devido, respectivamente, à maior facilidade de mistura ao longo da profundidade e à criação de maiores turbulências na superfície. Com base no que indicou a análise estatística, valores médios de $\mathrm{K}_{2}$, calculados com base nos resultados obtidos nos períodos seco e chuvoso, de $1,23 \mathrm{~d}^{-1}$, para o trecho mais montanhoso (T1) e de $0,65 \mathrm{~d}^{-1}$, nos demais trechos estudados (T2 e T3) do Rio Pomba, poderiam ser utilizados, sem proporcionar grandes erros em 
modelos de autodepuração desse curso d'água.

Góes (1997) obteve para o Riacho Quinze e o

Rio Pipiripau, cursos d'água localizados no Distrito Federal, valores de 4 a $8,5 \mathrm{~d}^{-1}$ para $\mathrm{K}_{2}$ calculado quando utilizou as equações de Langbien e Durum. Genereux \& Hemond (1992) determinaram o valor de $\mathrm{K}_{2}$ para um pequeno rio na Bacia Hidrográfica de Walker Branch, Tennesse, EUA, com vazão média anual menor que 17 $\mathrm{L} \mathrm{s}^{-1}$, tendo utilizado o método do traçador de gás sob fluxo constante. $\mathrm{O}$ valor encontrado para o coeficiente de reaeração foi de $118 \mathrm{~d}^{-1}$ a $139 \mathrm{~d}^{-1}$, valor esse muito maior do que os encontrados em rios de maiores vazões. Siqueira \& Cunha (1997), ao utilizarem seis equações empíricas na estimativa de $\mathrm{K}_{2}$ no Rio Meia Ponte, importante manancial de água para abastecimento da população da cidade de Goiânia, não observou variação significativa nos valores estimados, que ficaram entre 2 a $4 \mathrm{~d}^{-1}$. Bárbara (2006) ajustou valores de $\mathrm{K}_{2,}$ para o Rio Araguari (AP), na região Amazônica, na faixa de 0,01 a $1,4 \mathrm{~d}^{-1}$, valores mais próximos aos obtidos neste trabalho. Os valores de $\mathrm{K}_{2}$ obtidos neste trabalho também encontram-se na faixa de valores típicos citados por von Sperling (1996) para rios de diferentes características e condições de escoamento e que estão apresentados no Quadro 4.

De acordo com os valores apresentados no Quadro 4, o primeiro trecho (T1) do curso d'água se enquadrou como "rio rápido", no período seco e entre com "velocidade normal" e "rio rápido", no período chuvoso. Esta qualificação está associada ao fato desse trecho do rio coincidir com o das regiões mais montanhosas da bacia hidrográfica, estando próxima à nascente. No período seco, os trechos $\mathrm{T} 2$ e T3, coincidentes com partes da bacia hidrográfica com menor declividade, foram qualificados como de rios de "baixa velocidade" e "velocidade normal", respectivamente, enquanto no período chuvoso, o segundo e o terceiro trechos foram qualificados como rios de "velocidade normal". Com base nos resultados obtidos, pode-se verificar que, embora na época chuvosa haja aumento na vazão de água, o aumento na seção transversal de escoamento (seção molhada) não há significativo aumento na velocidade das águas, que é uma variável de influência direta no valor de $\mathrm{K}_{2}$.

Farage (2009) obteve valores de 1,20 a 5,30 $\mathrm{d}^{-1}$ no período chuvoso e de 0,17 a $1,02 \mathrm{~d}^{-1}$ no período de estiagem, no mesmo Rio Pomba (MG). Nunes (2008) encontrou valores de 0,016 a $5,560 \mathrm{~d}^{-1}$ no período chuvoso e de 0,016 a 1,605 $\mathrm{d}^{-1}$ no período de estiagem, no Rio Turvo Sujo (MG).

Valores de $\mathrm{K}_{2}$ obtidos por cálculo, utilizando-se as equações matemáticas ajustadas por Owens et al. (1976), citados por von Sperling (1996), escolhidas por serem as equações de maior aplicabilidade, já que foram ajustadas para profundidades e velocidades próximas às observadas no presente trabalho, estão apresentados no Quadro 5.

Quadro 4. Valores típicos de $\mathrm{K}_{2}$ (base "e" e obtidos sob temperatura de $20^{\circ} \mathrm{C}$ )

\begin{tabular}{lcc}
\hline Corpos d'água & profundo & raso \\
\hline Pequenas lagoas & 0,12 & 0,23 \\
Rios vagarosos, grandes lagos & 0,23 & 0,37 \\
Grandes rios com baixa velocidade & 0,37 & 0,46 \\
Grandes rios com velocidade normal & 0,46 & 0,69 \\
Rios rápidos & 0,69 & 1,15 \\
Corredeiras e quedas d'água & $>1,15$ & $>1,61$ \\
\hline
\end{tabular}

Fonte: Adaptado de Fair et al. (1973); Arceivala (1981), citados por von Sperling (1996)

Quadro 5. Valores de $K_{2}$ calculados utilizando-se a equação de Owens et al. (1976) (Equação 7), de faixa de aplicação: $0,1 \mathrm{~m} \leq \mathrm{H}<0,6 \mathrm{~m} \mathrm{e} 0,05 \mathrm{~m} \mathrm{~s}^{-1}<\mathrm{V}<1,5 \mathrm{~m} \mathrm{~s}^{-1}$, obtidos para os períodos secos e chuvosos

\begin{tabular}{ccccccccc}
\hline & \multicolumn{9}{c}{ Valores calculados } \\
\hline & \multicolumn{9}{c}{ Período seco } & \multicolumn{4}{c}{ Período chuvoso } \\
\hline & R1 & R2 & R3 & R4 & R1 & R2 & R3 & R4 \\
\cline { 2 - 10 } T1 & 11,4 & 11,7 & 12,7 & 15,0 & 17,4 & 16,4 & 16,5 & 14,9 \\
T2 & 4,7 & 4,7 & 4,8 & 5,2 & 5,0 & 5,1 & 5,0 & 4,2 \\
T3 & 3,0 & 3,1 & 3,1 & 3,1 & 3,0 & 2,7 & 2,9 & 2,4 \\
\hline
\end{tabular}


Quadro 6. Valores de $\mathrm{K}_{2}$ calculados utilizando-se a Equação 8, apresentada por RIBEIRO (2001)

\begin{tabular}{|c|c|c|c|c|c|c|c|c|}
\hline \multicolumn{9}{|c|}{ Valores calculados } \\
\hline & \multicolumn{4}{|c|}{ Período seco } & \multicolumn{4}{|c|}{ Período chuvoso } \\
\hline & R1 & $\mathbf{R 2}$ & $\mathbf{R 3}$ & $\mathbf{R 4}$ & R1 & $\mathbf{R 2}$ & R3 & R4 \\
\hline $\mathrm{T} 1$ & 8,1 & 8,3 & 8,9 & 10,2 & 11,6 & 11,0 & 11,0 & 10,1 \\
\hline $\mathrm{T} 2$ & 3,9 & 3,9 & 4,1 & 4,3 & 4,2 & 4,2 & 4,1 & 3,6 \\
\hline $\mathrm{T} 3$ & 2,7 & 2,8 & 2,8 & 2,8 & 2,7 & 2,5 & 2,6 & 2,2 \\
\hline
\end{tabular}

Quadro 7. Valores dos parâmetros da equação $K_{2}=a \cdot v^{b} \cdot H^{-c}$, obtidos por Regressão Não Linear, para os três trechos estudados do Rio Pomba, em que v está em m s${ }^{-1}$ e $\mathrm{H}$ em m, e $\mathrm{K}_{2}$ calculado utilizando as equações obtidas

\begin{tabular}{ccccccc}
\hline & & Período seco & & \multicolumn{3}{c}{ Período chuvoso } \\
\hline & T1 & T2 & T3 & T1 & T2 & T3 \\
\hline$a$ & 0,16 & 1,40 & 0,78 & 0,14 & 0,22 & 1,80 \\
$b$ & 0,29 & 2,74 & 0,18 & 1,50 & 2,64 & 1,00 \\
$c$ & 2,67 & 5,97 & 0,67 & 3,56 & 10,78 & 0,48 \\
\hline $\mathrm{r}^{2}$ & 0,80 & 0,89 & $<0,10$ & 0,91 & 0,95 & 0,99 \\
\hline $\mathrm{K}_{2}$ calc & 1,54 & 0,51 & 0,69 & 0,85 & 0,62 & 0,71 \\
\hline
\end{tabular}

Pode-se observar que os valores de $\mathrm{K}_{2}$ obtidos da equação de Owens et al. (1976) são muito maiores do que os valores obtidos neste trabalho usando a equação de Streeter-Phelps. Portanto, estas equações não se mostraram adequadas para a estimativa de $\mathrm{K}_{2}$ nos trechos estudados do Rio Pomba.

No Quadro 6, estão valores obtidos, por cálculo, para $\mathrm{K}_{2}$, utilizando-se a Equação 8, citada por Ribeiro (2001).

Os valores calculados utilizando-se a Equação 8 (RIBEIRO, 2001), considerandose um coeficiente de difusão molecular do oxigênio $\left(\mathrm{D}_{\mathrm{L}}\right)$ na água igual a $1,944 \times 10^{-4} \mathrm{~m}^{2} \mathrm{~d}^{-1}$, para uma temperatura de $15{ }^{\circ} \mathrm{C}$, foram maiores que os obtidos utilizando-se a Equação 5 de Streeter-Phelps (1925), mostrando, também, ser inadequada para estimativa do valor de $\mathrm{K}_{2}$ para $\mathrm{o}$ trecho estudado.

Ainda que, com base nos resultados da análise estatística, fosse recomendável o ajuste de equações para o conjunto de dados de $\mathrm{K}_{2}$ que não se mostraram significativamente diferentes, verificou-se ajuste ruim do modelo da Equação 6 ao conjunto dos dados. Por esta razão, optou-se pelo ajuste individual de cada trecho, para cada período de amostragem. Assim, após análise por
Regressão Não Linear, foram obtidos os seguintes parâmetros para a Equação $6\left(K_{2}=a \cdot v^{b} \cdot H^{c}\right)$, considerando-se os dados obtidos nos três trechos estudados do Rio Pomba, no período seco e chuvoso, conforme está apresentado no Quadro 7.

No geral, pode-se considerar que tenha havido ajuste satisfatório da equação aos dados obtidos, conforme pode ser verificado comparando-se os valores médios apresentados nos Quadros 2 e 3 com os apresentados no Quadro 7, o que indicou que o modelo potencial pode ser considerado adequado para associação entre as variáveis $\mathrm{K}_{2}$, v e H. Os parâmetros ajustados para a Equação 6 diferiram dos obtidos por Owens et al. (1976), citados por von Sperling (1996). Porém, considerando-se que, as equações foram obtidas, neste trabalho, para cursos d'água em escoamento sob condições tropicais e típicas da Zona da Mata mineira, entende-se que as equações obtidas deverão proporcionar estimativas de $\mathrm{K}_{2}$ mais próximas das realmente encontradas em regiões com condições edafoclimáticas semelhantes.

\section{CONCLUSÃO}

Com base nos resultados obtidos, pode-se concluir que: 
- Os valores de $\mathrm{K}_{2}$ estimados por equações apresentadas na literatura para rios com escoamento em condições semelhantes às do Rio Pomba foram sempre maiores que os obtidos quando utilizados dados coletados em campo e a equação de Streeter-Phelps;

- Modelos potenciais ajustaram-se bem aos dados obtidos, proporcionando a obtenção de equações de estimativa de $\mathrm{K}_{2}$ em função da velocidade e profundidade, nos trechos estudados do Rio Pomba;

- $\mathrm{O}$ coeficiente de reaeração $\left(\mathrm{K}_{2}\right)$ foi maior no ambiente de relevo montanhoso (cabeceiras do Rio Pomba ou trecho T1), que é o trecho de maior turbulência das águas e no qual foi obtido um valor médio de $1,23 \mathrm{~d}^{-1}$; nos demais trechos estudados (T2 e T3) do Rio Pomba valor médio obtido foi $0,65 \mathrm{~d}^{-1}$.

\section{REFERÊNCIAS BIBLIOGRÁFICAS}

AZEVEDO NETTO, J.M.; ARAÚJO, R.; FERNANDEZ, M.F.; ITO, A.E. Manual de hidráulica. $8^{\text {a }}$ ed.: Edgard Blücher, 1998.

BÁRBARA, V.F. Uso do modelo QUAL2E no estudo da qualidade da água e capacidade de autodepuração do Rio Araguari - AP (Amazônia). Goiânia: Universidade Federal de Goiás, 2006. 174 p. (Dissertação de mestrado)

FARAGE, J.A.P. Influência do uso e da ocupação do solo na qualidade da água e capacidade autodepurativa do Rio Pomba. Viçosa: Universidade Federal de Viçosa, 2009. 110 p. (Dissertação de mestrado)

GENEREUX, D.P.; HEMOND, H.F. Determination on Gas Exchange Rate Constants for a Small
Stream on Walker Branch Watershed. Tennessee: Water Resources Research, v.28, n.9, p.23652374, 1992.

GÓES, N.V. Controle da poluição na bacia do São Bartolomeu: o caso de esgotos sanitários do Vale do Amanhecer. Brasília: Universidade de Brasília, Departamento de Engenharia Civil e Ambiental, 1997. Projeto Final de Graduação.

NUNES D.G. Modelagem da autodepuração e qualidade da água do Rio Turvo Sujo. Viçosa: Universidade Federal de Viçosa, 2008. 109 p. (Dissertação de mestrado)

RIBEIRO, M.O. Estudo da Poluiçãa e Autodepuração nos Rios Melchior e Descoberto, na Bacia do Descoberto - DF-GO, com auxílio de modelos matemáticos de simulação de qualidade da água, para estudos de seu comportamento atual e futuro. Distrito Federal: PTARH-UNB, 2001. (Dissertação de mestrado).

SIQUEIRA, E.Q.; CUNHA, A.C. Cálculo do Coeficiente de Reaeração no Modelo QUAL2E Estudo de Caso: Rio Meia Ponte - GO. Vitória: XII SIMPÓSIO BRASILEIRO DE RECURSOS HÍDRICOS, 1997, Anais..., Vitória, 1997 CDRom.

STREETER, H.W.; PHELPS, E.B. A study of the pollution and natural purification of the Ohio River. Public Health Bulletin, $n^{\circ}$ 146. Washington, D.C, 1925.

VON SPERLING, M. Introdução à qualidade das águas e ao tratamento de esgotos. vol. 1: Princípios do tratamento biológico de águas residuárias. $2^{\mathrm{a}}$ ed. Belo Horizonte: DESA/ UFMG, 1995, 240p. 